\title{
Pengaruh Customer Based Brand Equity(CBBE) Merek Snack Terhadap Keputusan Pembelian Konsumen Pelajar di Kabupaten Grobogan Jawa Tengah
}

\author{
Sentot Suciarto A. \\ email: sentot.sa@unika.ac.id \\ Markus Widyanto \\ email: widy_uns@hotmail.com. \\ Rustina Untari \\ email: r.untari@gmail.com. \\ Program Studi Manajemen, Fakultas Ekonomi dan Bisnis \\ Universitas Katolik Soegijapranata
}

\begin{abstract}
The marketing of corn competitive product in Grobogan Regency was developed by increasing its value added by making corn snack. This research was done in Grobogan Regency toward 180 students comprising Elementary School, Yunior and Senior High School, each 60 respondents consuming corn snack. Using regression analysis, it was known that there is significant influence from variables constructing Customer Based Brand Equity (CBBE) by Keller. Variables which influence positive and significant were Brand Imagery, Brand Performance and Brand Resonance. It was found that $R$ equals 0.551 and adjusted $R$ square or determinant coefficient was 0.279 or influence of CBBE toward BuyingDecision was 27.9 percent.
\end{abstract}

Keywords: CBBE, brand salience, brand performance, brand resonance, purchasedecision.

\section{PENDAHULUAN}

KabupatenGrobogan sebagai lokasitechnopark pangan merupakan lumbung pangan Indonesia dengan luas wilayah $1.976 \mathrm{~km}^{2}$ dan penduduk 1.325 jiwa dalam BPS 2017. Produksi dari lahan pertanian yang ada meliputi padi, jagung, kedelai, kacang hijau dan lain-lain. Kehadiran tehcnopark mempunyai pesan ingin memperkenalkan teknologi di dalam pertanian. Peningkatan nilai tambah hasil pertanian jagung diupayakan dengan membuat aneka makanan salah 
satunya snack terbuat dari jagung. Pengenalan snack jagung tidaklah mudah karena sudah banyak merek ternama yang lebih dulu masuk pasar.

Data dari top brand index untuk kategori makanan snack jagung adalah Cheetos (TBI 48,7\% TOP), Happytos (TBI 15,1 TOP), Twistko (TBI 8,1\%), dan Turbo (TBI 5,4\%). Di lain pihak ada Top Brand Index untuk merek snack mie (Mie Kremezz, Gemez, Soba, Mie Remez dan Anak Mas ) dan snack kentang (Chitato, Potato, Lays, Piattos, dan Leo). Seringkali anak tidak bisa membedakan yang berbahan jagung atau kentang. Merek menjadi penting ketika konsumen memilih produk berdasarkan merek yang diingat, bukan bahan pembuatnya.Selain itu tampilan packaging secara visual menarik dan rasa yang cocok dengan selera membuat pilihan dan keputusan pembelian konsumen anak (Suciarto dkk. , 2017)

Dari sudut pandang konsumen, bagaimanakah pengaruh kekuatan merek ini terhadap keputusan pembelian mereka. Beberapa variabel pembentuk kekuatan merek dari sudut pandang konsumen diteliti. Variabel tersebut meliputi brand salience, brand imagery, brand performance, brand feeling, brand judgement, dan brand resonance. Penelitian ini mengambil responden anak muda karena nantinya yang menjadi pasar jangka panjang adalah mereka ini.

\section{TINJAUAN PUSTAKA}

Merek atau brand berasal dari kata brandr, yang berarti membakar, karena dulu untuk mengenali hewan ternak piaraan dicap dengan besi panas sehingga kulitnya terbakar dan membuat tanda pengenal. Merek adalah nama, istilah, tanda, simbol, desain, atau kombinasi dari semuanya untuk membedakan dari produk produsen yang lain (Keller, 2013). Peran merek dalam kehidupan manusia mampu membuat lebih baik karena mempermudah pengambilan keputusan, mengurangi resiko kesalahan memilih produk, dan memperbesar kepuasan konsumen (Keller, 2010).Elemen merek, kadang-kadang disebut identitas merek, adalah perangkat yang dapat mengidentifikasi dan membedakan merek. Yang utama adalah nama merek, URL, logo, simbol, karakter, juru bicara, slogan, 
jingle, paket, dan papan nama.Sebuah merek elemen yang memberikan kontribusi positif terhadap ekuitas merek menyampaikan atau menyiratkan nilai tertentu asosiasi atau tanggapan.Pada umumnya, ada enam kriteria dalam memilih elemen merek diantaranya adalah: memorability, meaningfulness, likability, transferability, adaptability, dan protectability. (Keller, 2013)

- Memorability: Wajib dalam membangun brand equity adalah mencapai brand awareness. Dimana untuk mencapainya suatu Merk harus dapat diingat dan suatu pekerjaan penting bagi seorang marketer untuk membuat suatu merk ini dapat diingat.Misalnya dengan menggunakan suatu nama, simbol, logo unik yang memberi kemudahan bagi para konsumen untuk mengingatnya.

- Meaningfulness: Arti kata meaningfull ini dapat dibentuk oleh dua factor penting yaitu descriptive dan persuasive. Dimana faktor deskriptif disini adalah merupakan suatu informasi umum mengenai product category.Sedangkan faktor persuasif memberikan informasi yang specifik mengenai atribut dan manfaat dari suatu Merk.

- Likability: Kriteria likability ini mengandung pengertian bahwa suatu Merk harus menarik perhatian konsumen. Para marketer biasanya memberikan suatu tampilan visual yang membuat si konsumen tertarik untuk mengamatinya.

Ketiga kriteria di atas merupakan kriteria utama yang sebenarnya membentuk brand equity. Hal ini dikarenakan ketiga kriteria di atas merupakan sarana komunikasi yang terbaik untuk membangun kesadaran dari pihak konsumen itu sendiri.

- Transferability: Kriteria transferability ini mengandung pengertian bahwa suatu Merk harus memiliki suatu kemudahan untuk dipindah ke lintas produk kategori yang lain serta dapat digunakan pada kondisi geografis dan budaya yang berbeda.

- Adaptable: Pertimbangan kelima dalam memilih brand elements yang tidak kalah penting yaitu adaptability. Hal ini dikarenakan mungkin saja adanya 
perubahan nilai dan pendapat yang notabene bersifat sementara. Oleh karena itu, brand element harus terus diperbarui setiap saat untuk memenuhi tuntutan dari konsumen yang memiliki selera yang berubah-ubah setiap saat.

- Protectability: Memilih brand element ini harus memiliki perlindungan secara legal apabila suatu produk sudah terjun ke dalam pasar. Kriteria protectability ini dimasukkan ke dalam kriteria terakhir dalam memiliki suatu elemen merek, karena adanya kemudahan bagi pihak pesaing untuk meniru atau menyamarkan merk tersebut, tetapi seorang marketer harus pandai-pandai menawarkan keunikan akan suatu produknya sehingga menyulitkan bagi pesaing untuk menirunya.

\section{Ekuitas Merek}

Konsep ekuitas merek atau brand equity muncul pada tahun 1980an dan menjadi perhatian akademisi (Fayrene dan Lee, 2011). Merek menjadi aset yang berharga bagi perusahaan. Ekuitas merek yang tinggi membawa peluang untuk mendapatkan perluasan pasar, tahan menghadapi promosi pesaing, dan menjadi hambatan masuk bagi pesaing.Konsep merek menurut Keller telah didahului oleh Aaker yang juga melihat merek dari sudut pandang konsumen. Perspektif terhadap Ekuitas merek dapat dipandang dari perspektif financial, perspektif konsumen, dan perspektif karyawan/pegawai (Baalbaki, 2012).

Dari perspektif finansial, pengukuran ekuitas merek berpusat pada harga saham atau penggantian merek. Ekuitas Merek merupakan arus kas inkremental untuk produk bermerek yang melebihi arus kas untuk produk yang tanpa merek. Kekuatan merek dilihat sebagai nilai merek dapat dilihat sebagai aset yang terpisah di neraca.

Dari perspektif konsumen atau Customer-based Brand Equity, disingkat CBBE, melihat dari psikologi kognitif. Banyak diikuti akademisi dan praktisi karena bila merek tidak bermakna atau bernilai bagi konsumen maka akan tidak berarti bagi investor, pabrikan, ataupun pengecer. CBBE terjadi ketika konsumen familiar dengan merek dan mempunyai asosiasi merek yang favourabel, kuat dan 
unik dalam memorinya. CBBE yang positif akan menguntungkan karena konsumen akan berusaha mencari produk bermerek tersebut, bersedia membayar lebih tinggi, dan membuat komunikasi pemasaran efektif.

Perspektif karyawan atau pegawai adalah dari sudut pandang karyawan yang mempunyai efek dari pengetahuan produk terhadap lingkungan dan budaya kerjanya. Ada tiga dimensi perspektif karyawan terhadap merek yaitu pengetahuan merek (brand knowledge), kejelasan peran (role clarity) dan komitmen merek (brand commitment). (Farjam dan Hongyi, 2015). Dengan pengeatahuan merek yang kuat maka karyawan akan menghargai merek, membuat kontrak psikologis dan mengurangi keluar masuk karyawan.

Secara teoritis, konsep ekuitas merek dapat digambarkan sebagai berikut:

Diagram1. Perspektif Ekuitas Merek

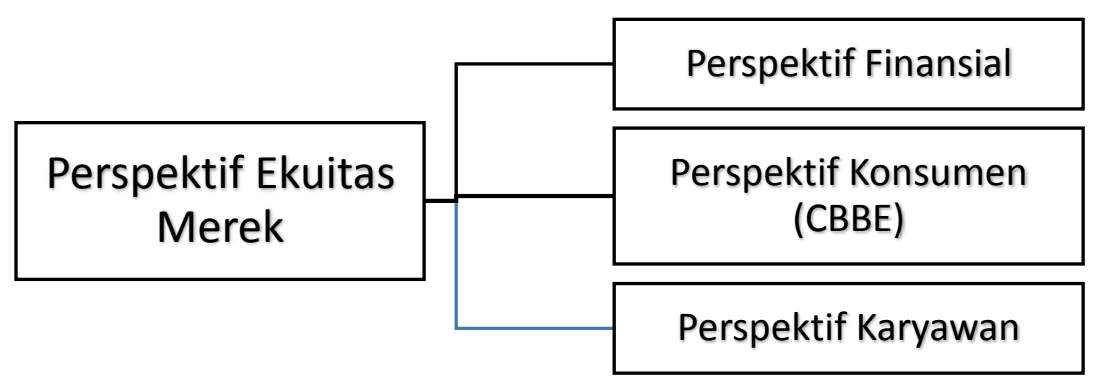

Sumber: Farjam dan Hongyi, 2015.

Beberapa konsep CBBE dikembangkan oleh Aaker (1992), Keller (1993), Yoo dan Donthu (2002), dan Luming Wang dan Adam Finn (2013). Aaker melihat ada 5 dimensi aset yang bernilai dari merek yaitu loyalitas merek, kesadaran merek, perceived brand quality, asosiasi merek dan aset merek yang lain. Keller melihat ada piramida yang bertingkat membentuk ekuitas merek. Paling bawah adalah tingkatan brand salience yang berisi pengetahuan merek, yang mudah dikenali. Di level kedua ada brand imagery dan brand performance. Di level ketiga ada brand feelings dan brand judgments. Dan di level 4 ada brand resonance. Yoo dan Donthu melihat ekuitas merek sebagai model yang meliputi 
tiga komponen, yaitu komponen aktivitas pemasaran 4P, komponen ekuitas Aaker, dan keseluruhan ekuitas merek. Sedangkan Luming Wang dan Adam Finn melihat keunikan dan persepsi kualitas menjadi formatif CBBE. Juga kognitif dan emosi tentang merek.

\section{Ekuitas Merek CBBE}

Premis dasar model CCBE adalah bahwa kekuatan suatu merek terletak pada apa yang telah dipelajari, dirasakan, dilihat dan didengar oleh pelanggan tentang merek tersebut sebagai akibat dari kelebihan mereka dari waktu ke waktu. Dengan kata lain, kekuatan merek terletak pada apa yang ada di benak pelanggan. Keller (2013) secara formal mendefinisikan ekuitas merek berbasis pelanggan sebagai efek diferensial yang dimiliki pengetahuan merek terhadap respons pelanggan terhadap pemasaran ubin atau memperlakukan merek.

Beberapa marketer membedakan aspek psikologi merk dengan aspek pengalaman. Aspek pengalaman merupakan gabungan seluruh point pengalaman berinteraksi dengan merk, atau sering disebut brand experience. Aspek psikologis, sering direferensikan sebagai brand image, adalah citra yang dibangun dalam alam bawah sadar konsumen melalui informasi dan ekspektasi yang diharapkan melalui produk atau jasa. Pendekatan yang menyeluruh dalam membangun merk meliputi struktur merk, bisnis dan manusia yang terlibat dalam produk (Keller, 2013).

Dari berbagai konsep CBBE tersebut, peneliti menggunakan enam variabel pembentuk CBBE Keller menjadi variabel pengaruh Keputusan Pembelian sehingga memperkuat versi Keller yang melihat CBBE sebagai piramida dimensi merek. 
Diagram 2. Piramida Pembentuk CBBE versi Keller
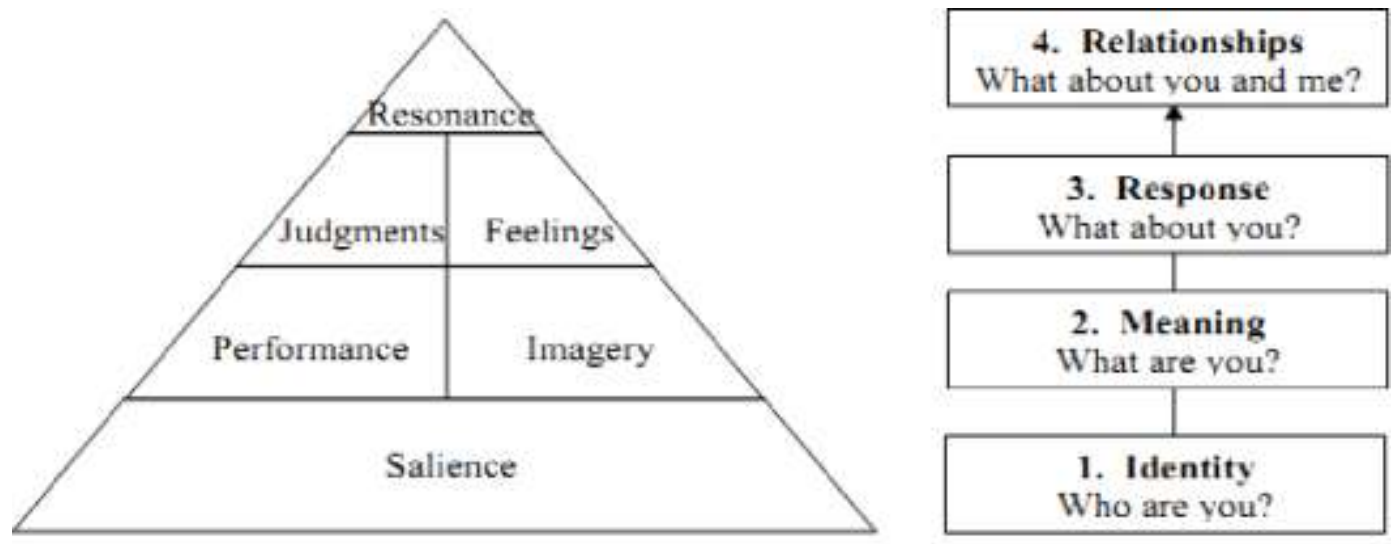

Sumber: Keller, 2011.

Keenam variabel pembentuk CBBE ini oleh Keller dijabarkan lebih jauh ke dalam pengertian yang dialami oleh konsumen. Pengalaman yang dipelajari oleh konsumen menjadi dasar dalam pengambilan keputusan pembelian produk. Dapat digambarkan dalam diagram berikut:

Diagram 3. Penjabaran Sub Dimensi Pembentuk CBBE versi Keller

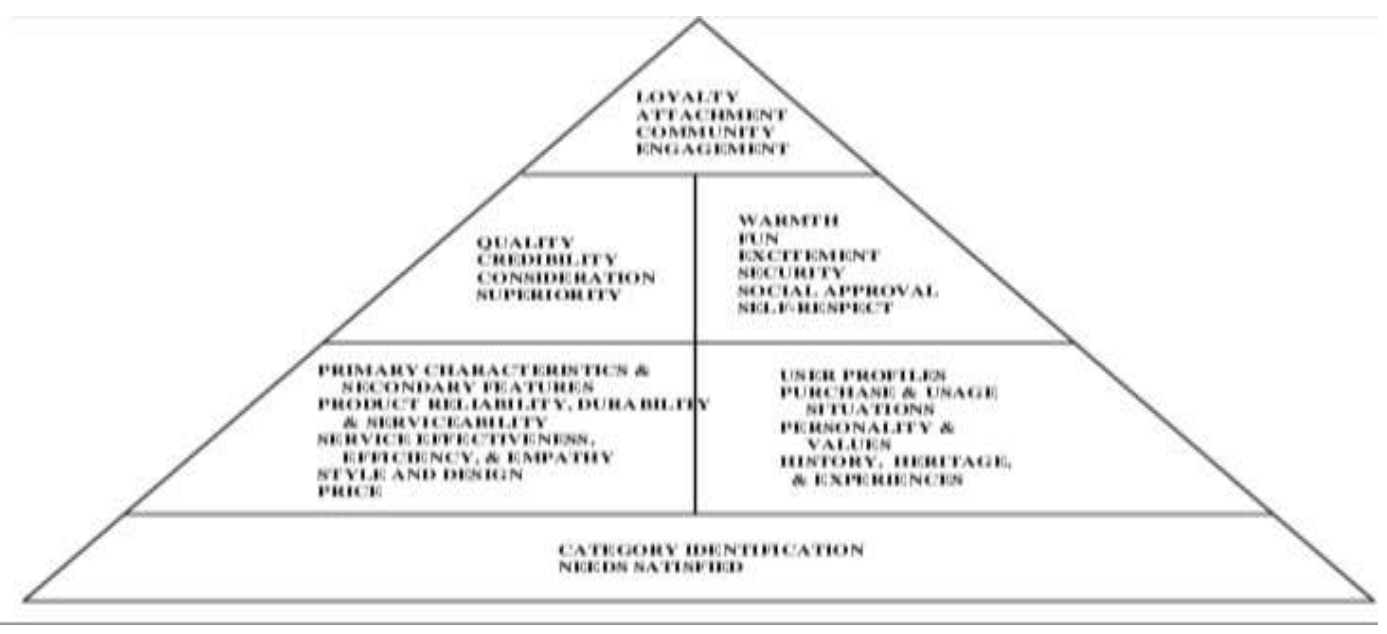

Sumber: Keller, 2013. 
Brand Salience mengukur berbagai aspek kesadaran akan merek dan bagaimana mudahnya dan seringnya merek muncul dalam berbagai situasi dan lingkungan. Bagaimana merek menjadi TOM (top of mind), dan dengan mudah dikenali atau diingat. Kategori produk atau pengingat apa yang mudah dikenali pelanggan. Misal mudah dikenalinya nama merek, logo, symbol, dan sebagainya terhadap asosiasi di ingatan pelanggan. Merek menjadi fungsi dasar yang mampu memuaskan kebutuhan konsumen.

Brand performance adalah kunci inti ekuitas merek. Pengaruh utamanya terhadap apa yang mereka dengar dan yang dialami pelanggan atas merek. Hal ini menjadi apa yang diceritakan pelanggan dalam komunikasi mereka. Kepuasan dan pemenuhan kebutuhan menjadi kunci sukses pemasaran baik produk yang kelihatan maupun jasa, organisasi, atau orang. Paling tidak produk sesuai harapan atau melampaui harapan. Brand performance menunjuk pada kebutuhan fungsional pelanggan yang terpenuhi. Hal ini terkait penilaian objektif tentang kualitas, tentang kebutuhan pelanggan secara ekonomis, estetis, dan utilitarian terpuaskan karena adanya produk atau jasa tersebut.

Brand imagery merupakan pembentuk CBBE yang tergantung pada karakteristik produk ekstrinsik. Bisa memenuhi kebutuhan pelanggan secara psikologis dan sosial. Ini cara berpikir konsumen tentang merek secara abstrak, dibandingkan dengan berpikir produk apa adanya. Jadi bayangan atau imagery lebih tidak kelihatan, dan konsumen bisa melakukan bayangan asosiatif terhadap merek baik berdasar pengalamannya maupun berdasarkan iklan yang dilihat atau informasi lainnya dari mulut ke mulut. Yang tidak kelihatan itu dapat dihubungkan dengan merek terutama ada 4 hal yaitu profil pengguna, situasi pembelian dan pemakaian, personalitas dan nilai, serta sejarah-heritagepengalaman.

Brand jugments adalah opini personal pelanggan tentang dan evaluasi atas merek yang dibentuk konsumen dengan meletakkan bersama-sama semua asosiasi imagery dan brand performance bersama-sama. Pelanggan bisa melakukan semua 
jenis judgmen terhadap suatu merek, tetapi ada 4 tipe yang penting yaitu judgmen tentang kualitas, kredibilitas, pertimbangan dan superioritas.

Brand feelings adalah respons dan reaksi emosional pelanggan. Perasaan ini juga berkaitan dengan keterkaitan sosial yang muncul dari merek. Perasaan apa yang dimunculkan dari program atau sarana lainnya. Bagaimanakah merek mempengaruhi perasaan pelanggan tentang diri mereka sendiri dan hubungannya dengan orang lain. Perasaan ini bisa sedang atau kuat, bisa juga positif atau negatif. Misal merek Kevin Robert dari Saatchi \& Saatchi menjadi nama yang mengikat perasaaan konsumen dengan keinginan dan aspirasi tanda cinta.

Di dalam ujung atas piramida adalah resonansi merek atau brand resonance. Hal ini menjadi penting dipahami apa itu brand resonance.Resonansi merek menggambarkan tingkat identifikasi yang dimiliki pelanggan dengan merek dan sejauh mana pelanggan merasa bahwa mereka "selaras" dengan merek, contoh Harley Davidson dan Apple. Resonansi merek dipecah menjadi empat kategori: 1) kesetiaan perilaku, 2) kelekatan sikap, 3) rasa komunitas, dan 4) keterlibatan aktif. Kesetiaan perilaku: seberapa sering pelanggan membeli merek dan berapa banyak yang mereka beli. Attitudinal attachment: pelanggan harus memiliki sikap positif untuk melihat suatu merek sebagai sesuatu yang istimewa dalam konteks yang lebih luas. Rasa komunitas: Identifikasi dengan merek komunitas dapat mencerminkan fenomena sosial yang penting di mana pelanggan dapat merasakan hubungan keluarga atau afiliasi dengan orang lain yang terkait dengan merek tersebut. Komunitas merek dapat eksis secara online atau offline. Keterlibatan aktif: Ini mungkin merupakan penegasan loyalitas merek yang paling kuat, hal itu terjadi ketika pelanggan bersedia menginvestasikan waktu, energi, uang, atau sumber daya lain di luar yang dikeluarkan selama pembelian atau konsumsi merek. Perhatian yang rasional dapat memuaskan kebutuhan utilitarian, sedangkan masalah emosional dapat memuaskan kebutuhan psikologis atau emosional.

Berdasarkan variabel pengaruh pembentuk CBBE terhadap keputusan pembelian, maka dapat dibuat kerangka pikir sebagai berikut: 


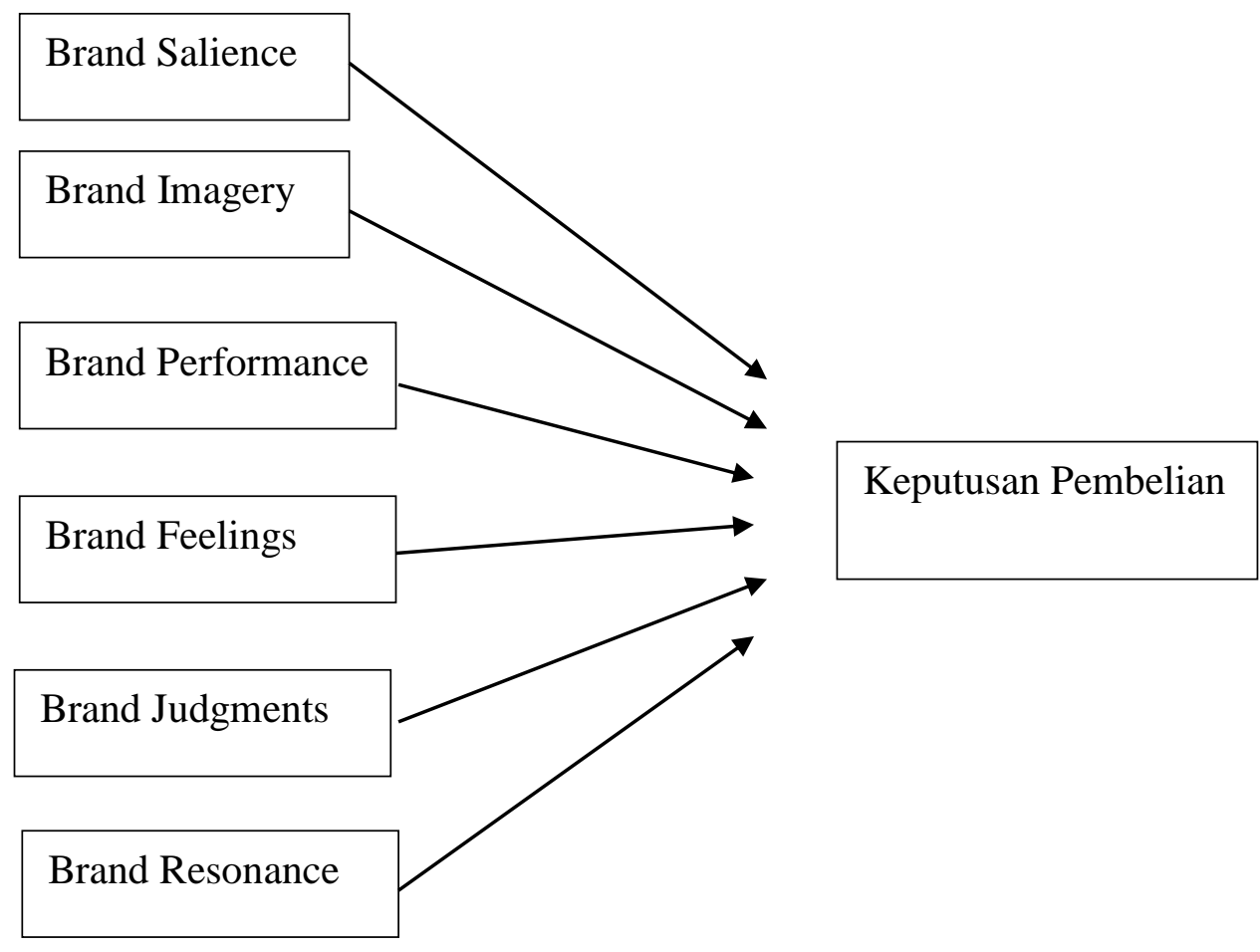

Gambar 1. Kerangka Pikir Penelitian

\section{Hipotesis}

Berdasarkan permasalahan yang diteliti, maka hipotesis penelitian adalah terkait dengan apakah variabel pembentuk CBBE berpengaruh terhadap keputusan pembelian. Ada enam variabel yang dihipotesiskan mempengaruhi keputusan pembelian yaitu brand salience, brand performance,brand imagery, brand judgement,brand feelings, dan brand resonance. Diduga keenam variabel ini secara individual dan secara bersama-sama berpengaruh positif dan signifikan terhadap keputusan pembelian.

Definisi operasional dari variabel penelitian ini adalah terkait dengan beberapa variabel. Brand salience adalah unsur merek yang menonjol yang mudah dikenali responden. Brand imagery adalah kesan merek yang mencerminkan rasa snack, misal merah rasa pedas, kuning rasa jagung manis. Brand performance adalah kegunaan snack yang cocok menjadi cemilan atau 
klethikan. Brand feelings adalah rasa perasaan senang mendapatkan snack sesuai kesukaannya. Brand judgment adalah kesesuaian snack atau kecocokan dengan rasa yang saya pilih. Brand resonance adalah selalu ingat akan merek tertentu. Keputusan pembelian adalah merek terkenal yang membuat saya memutuskan membeli snack tersebut.

\section{Metodologi Penelitian}

a. Data

Data primer dikumpulkan dengan kuesioner oleh peneliti melalui surveyor terkait dengan tanggapan responden mengenai identitas responden dan terkait variabel pengaruh keputusan pembelian tersebut. Data dikumpulkan antara bulan Juni dan Juli 2018.

\section{b. Populasi \& Sampel}

Penelitian ini mengambil populasi di sekitar Kota Purwodadi Kabupaten Grobogan. Dipilih konsumen snack meliputi anak-anak muda. Jumlah populasi tidak diketahui. Sampel ditetapkan secara purposive sampling, dipilih sampel dengan kriteria yang mengkonsumsi snack berbahan jagung. Responden ditetapkan dari anak-anak Sekolah Dasar (SD), Sekolah Menengah Pertama (SMP), dan Sekolah Menengah Atas (SMA). Besar sampel sejumlah 180 responden meliputi 60 responden masing-masing untuk SD, SMP dan SMA.

\section{c. Variabel}

1) Variabel Independen meliputi variabel pembentuk customer based brand equity yaitu brand salience, brand imagery, brand performance, brand feelings, brand judgment, dan brand resonance.

2) Variabel Dependen yang dipengaruhi oleh variabel independen tersebut adalah keputusan pembelian.

\section{d. Teknik analisis}

Untuk menganalisis data penelitian ini digunakan analisis regresi linier berganda. 


\section{Hasil}

Responden survey untuk penelitian ini adalah 180 para pelajar SD, SMP, dan SMA. Dari seluruh responden, terdapat 50,6 persen laki-laki dan 49,4 persen wanita. Uang saku para responden sebagian besar di bawah Rp.10.000 (73,9 \%) dan sisanya sekitar Rp.10.001 - Rp.30.000 ( 26,1 \%).Berdasarkan tanggapan responden, diketahui bahwa nama merek yang banyak dipilih responden untuk dibeli adalah Cheetos (38,9\%), Komo (35,5\%), Twisko (5,0 \%), marning tanpa merek $(5,6 \%)$ dan sisanya ada berbagai merek (21,1\%). Merek produk snack yang banyak dikonsumsi responden pada uang saku di bawah Rp.10.000 adalah merek Cheetos ( $31,6 \%$ ) dan Komo ( $26,1 \%$ ).

Tabel 1 Identitas Responden

\begin{tabular}{ccccccc}
\hline \multirow{2}{*}{$\begin{array}{c}\text { Keterangan } \\
\text { Pendidikan }\end{array}$} & \multicolumn{2}{c}{ Laki - laki } & \multicolumn{2}{c}{ Perempuan } & \multicolumn{2}{c}{ Total } \\
\cline { 2 - 7 } & F & $\%$ & F & $\%$ & F & $\%$ \\
\hline \hline SD & 42 & 23,3 & 18 & 10,0 & 60 & 33,33 \\
\hline SMP & 25 & 13,9 & 35 & 19,4 & 60 & 33,33 \\
\hline SMA & 24 & 13,3 & 36 & 20,0 & 60 & 33,34 \\
\hline
\end{tabular}

Tabel 1 Identitas Responden (lanjutan)

\begin{tabular}{ccccccc}
\hline \multirow{2}{*}{$\begin{array}{l}\text { Keterangan } \\
\text { Pendidikan }\end{array}$} & \multicolumn{2}{c}{ Laki - laki } & \multicolumn{2}{c}{ Perempuan } & \multicolumn{2}{c}{ Total } \\
\cline { 2 - 7 } & $\mathrm{F}$ & $\%$ & $\mathrm{~F}$ & $\%$ & $\mathrm{~F}$ & $\%$ \\
\hline \hline Uang Saku & & & & & & \\
\hline Rp. 5.000.ke bawah & 34 & 18,9 & 15 & 8,3 & 49 & 27,2 \\
\hline $5001-10.000$ & 40 & 22,2 & 44 & 24,4 & 84 & 46,7 \\
\hline $10.001-15.000$ & 8 & 4,4 & 17 & 9,4 & 25 & 13,9 \\
\hline $15.001-20.000$ & 9 & 5,0 & 11 & 6,1 & 20 & 11,1 \\
\hline 20.001 ke atas & 0 & 0,0 & 2 & 1,1 & 2 & 1,1 \\
\hline Total & 91 & 50,6 & 89 & 49,4 & 180 & 100,0 \\
\hline MerekProduk & & & & & & \\
\hline Cheetos & 42 & 23,3 & 28 & 15,6 & 70 & 38,9 \\
\hline Komo & 31 & 17,2 & 32 & 17,8 & 63 & 35,0 \\
\hline Twisko & 4 & 2,2 & 5 & 2,8 & 9 & 5,0 \\
\hline Lainnya & 14 & 7,9 & 24 & 13,2 & 38 & 21,1 \\
\hline
\end{tabular}

Sumber: Data primer Juli 2018. 
Hasil analisis regresi memperlihatkan persamaan regresi yang terbentuk adalah

$$
\begin{aligned}
\mathrm{KP}= & 6,104+0,276 \mathrm{BSL}+0,744 \mathrm{BIMG}+1,538 \mathrm{BPF}-0,054 \mathrm{BFL}+ \\
& 0,273 \mathrm{BJG}+1,307 \mathrm{BRS}
\end{aligned}
$$

Keterangan:

$\begin{array}{ll}\text { KP }: \text { keputusan Pembelian } & \text { BFL : brand feeling } \\ \text { BSL : brand salience } & \text { BJG : brand judgement } \\ \text { BIMG : brand imagery } & \text { BRS : brand resonance } \\ \text { BPF : brand performance } & \end{array}$

Selain persamaan regresi tersebut, dapat diketahui bahwa dari keenam variabel tersebut hanya tiga variabel yang berpengaruh positif dan signifikan. Ketiga variabel itu adalah brand imagery, brand performance dan brand resonance.

Tabel 2Signifikansi Koefisien Regresi

\begin{tabular}{ccccccc}
\hline \multirow{2}{*}{ Model } & \multicolumn{2}{c}{$\begin{array}{c}\text { Unstandardized } \\
\text { Coefficients }\end{array}$} & \multicolumn{2}{c}{$\begin{array}{c}\text { Standardized } \\
\text { Coefficients }\end{array}$} & \multirow{2}{*}{$\mathrm{t}$} & \multirow{2}{*}{ Sig. } \\
\cline { 2 - 6 } & $\mathrm{B}$ & Std. Error & Beta & & \\
\hline \hline & (Constant) & 6.104 & 2.071 & & 2.947 & .004 \\
\hline & BSL & .276 & .335 & .057 & .824 & .411 \\
\hline & BIMG & .744 & .312 & .173 & 2.388 & .018 \\
\hline & BPF & 1.538 & .409 & .265 & 3.763 & .000 \\
\hline & BFL & -.054 & .368 & -.011 & -.146 & .884 \\
\hline & BJG & .273 & .435 & .050 & .626 & .532 \\
\hline BRS & 1.307 & .277 & .322 & 4.719 & .000 \\
\hline
\end{tabular}

Keterangan: Dependent Variable: KP (keputusan pembelian)

Dari koefisien determinasi, diketahui bahwa pengaruh variabel pembentuk customer based brand equity ini sebesar 27,9 percent. Dengan korelasi berganda sebesar 0,551 . 
Tabel 3Model Summary

\begin{tabular}{ccccc}
\hline Model & $\mathrm{R}$ & R Square & $\begin{array}{c}\text { Adjusted R } \\
\text { Square }\end{array}$ & $\begin{array}{c}\text { Std. Error of the } \\
\text { Estimate }\end{array}$ \\
\hline \hline 1 & $.551^{\mathrm{a}}$ & .304 & .279 & 3.11916 \\
\hline
\end{tabular}

a. Predictors: (Constant), BSL, BIMG, BPF, BFL, BJG, BRS

Secara keseluruhan bersama-sama seluruh variabel berpengaruh terhadap keputusan pembelian dimana signifikansi F mendekati nol.

Tabel 4ANOVA ${ }^{\mathrm{a}}$

\begin{tabular}{lllrrrr}
\hline \multirow{2}{*}{ Model } & $\begin{array}{l}\text { Sum of } \\
\text { Squares }\end{array}$ & df & Mean Square & F & Sig. \\
\hline \hline \multirow{2}{*}{1} & Regression & 733.711 & 6 & 122.285 & 12.569 & $.000^{\mathrm{b}}$ \\
\cline { 2 - 7 } & Residual & 1683.150 & 173 & 9.729 & & \\
\cline { 2 - 7 } & Total & 2416.861 & 179 & & & \\
\hline
\end{tabular}

a. Dependent Variable: KP (keputusan pembelian)

b. Predictors: (Constant), BSL, BIMG, BPF, BFL, BJG, BRS

\section{Pembahasan}

Variabel pembentuk CBBE (customer based brand equity) mempunyai pengaruh signifikan terhadap keputusan pembelian. Menurut Keller, brand equityperlu dilihat dari perspektif konsumen, bukan hanya dari sisi produsen atau penjual. Kekuatan merek dimata konsumen membuat pembelian berulang dan mempengaruhi pengambilan keputusan konsumen untuk membeli produk. Merek yang dipilih konsumen untuk dibeli sebagian besar pada beberapa merek, misal Cheetos dan Komo. Merek ini dimata konsumen mempunyai pengaruh kuat dari aspek brand image, brand performance danbrand resonance.

Dalam pandangan konsumen, bila mereka membutuhkan snack saat istirahat sekolah atau saat senggang, mereka cenderung memilih merek yang mereka pilih (brand imagery). Selain itu snack berbahan jagung ini memiliki kesesuaian 
dengan kebutuhan mereka (brand performance). Dengan pengalaman mengkonsumsi yang sesuai dengan kebutuhan mereka, mereka memutuskan membeli merek produk yang melekat erat di benak mereka (brand resonance).

Hal ini sesuai dengan temuan penelitian sebelumnya (Malik dkk, 2013) yang menemukan kesadaran akan merek berpengaruh signifikan. Demikian juga penelitian Alex YS Lin yang bahwa CBBE mempunyai hubungan positif dan berarti (Lin dkk, 2015) maupun kesesuaian faktor pendukung CBBE dalam klaster etnosentris dalam memilih skin-moisturizer (Garlina, 2014).

Beberapa komponen pembentuk CBBE tidak signifikan berpengaruh terhadap keputusan pembelian, meliputi brand salience, brand feelings, dan brand judgments. Di dalam keputusan konsumen membeli produk snack, konsumen cenderung mengabaikan unsur yang menonjol seperti nama merek yang ditulis besar karena anak-anak dalam berbelanja cenderung berombongan atau ramairamai dengan temannya saat istirahat sekolah atau saat pulang dari sekolah. Ketika seseorang memilih maka akan diikuti oleh anak yang lain. Hal ini membuat mereka tidak memperhatikan unsur brand salience. Di lain pihak mereka juga tidak memperhatikan brand feelings dan brand jugments.

\section{Kesimpulan}

Berdasarkan analisis regresi linier berganda diketahui ada pengaruh secara bersama-sama yang signifikan dari variabel pembentuk CBBE terhadap keputusan pembelian. Ada tiga koefisien variabel yang mempunyai pengaruh positif dan signifikan yaitu variabel brand imagery, brand performance dan brand resonance. Berdasarkan signifkansi pengaruh tersebut maka perlu diketahui oleh para pelaku usaha agar tetap mempertahankan produknya sesuai dengan kebutuhan dan persepsi konsumen akan pemanfaatan snack jagung di saat senggang atau santai.

Tantangan bagi produk lokal untuk membuat produk snack yang kualitas produknya setara dengan snack yang banyak menjadi pilihan konsumsi responden(brand resonance) dan membuat merek yang konsisten dipelihara dan 
dijaga sehingga menjadi kuat. Biasanya produk lokal meniru produk pabrikan dengan merek terkenal (brand imagery) dengan harga di bawah dan kualitas mendekati atau setara maka akan ikut terangkat juga mereknya. Inilah yang merupakan Brand performance, maka perlu diusahakan terus menerus.Pengembangan produk agar rasa dan kekeringan terjaga membuat konsumen merasa puas, terpenuhi kebutuhannya.

\section{Daftar Pustaka}

Baalbaki, Sally Samih. (2012). Consumer Perception of Brand Equity Measurement: A New Scale. page 16. Dissertation of Doctor Philosophy. Texs: University of North Texas.

Lin, Alex YS, Yu -Ting Huang dan Meng-Kai Lin. (2015). Customer-based Brand Equity: The Evidencerom China. Contemporary Management Research. Vol 11. No.1 March. page 75 - 94.

Farjam, Sanaz dan Xu Hongyi.(2015). Reviewing the Concept of Brand Equity and Evaluating Consumer-Based Brand Equity (CBBE) Models. International Journal of Management Science and Business Administration. Volume 1. Issue 8 July . page 14-29.

Fayrene, Chieng YL dan Goi Chai Lee. (2011).Customer-Based Brand Equity: A Review Literature. Research World. Journal of Arts Science \& Commerce. Vol II Issue 1. January.

Garlina, Yossy Hanna. (2014). Comparison of Skin Moisturizer : Consumer-based Brand Equity (CBBE) Factors in Cluster Based on Consumer Ethnocentrism. Journal the Winners. Vol 15. No 2. September. Page 115122.

Keller, Kevin Lane. (2010). The New Branding Imperatives: Insight for the New Marketing Realities.Cambridge Massachusentts: the Marketing Science Institute.

Keller, Kevin Lane. (2013). Strategic Brand Management: Building, Measuring and Managing Brand Equity. Fourth Edition. Global Edition. Boston: Pearson.

Malik, Muhammad Ehsan, M. Mudasar Gafoor, dan Hafiz Kashif Iqbal. (2013). Importance of Brand Awareness and Brand Loyalty in Assesing Purchase Intentions of Consumer. International Journal of Business and Social Science. Vol 4. No. 5. May.page 167 - 171.

Suciarto, Sentot Athanasius, MY Dwi Hayu Agustini, dan M.Widyanto. (2017). Influence of Brands Toward Purchase Intention of Corn Snack Product in Grobogan Regency Central Java Indonesia. Proceeding of International Conference on Economics, Business and Management Research (ICEBMR). Yogjakarta: Sanata Dharma University. 